\title{
Paclitaxel-loaded iron platinum stealth immunomicelles are potent MRI imaging agents that prevent prostate cancer growth in a PSMA-dependent manner
}

\author{
This article was published in the following Dove Press journal: \\ International Journal of Nanomedicine \\ 4 August 2012 \\ Number of times this article has been viewed
}

\author{
Robert M Taylor ${ }^{1,2}$ \\ Laurel O Sillerud ${ }^{1,3}$ \\ 'Department of Biochemistry \\ and Molecular Biology, ${ }^{2} \mathrm{New}$ \\ Mexico Cancer Nanoscience and \\ Microsystems Training Center, \\ ${ }^{3}$ UNM Cancer Center, University \\ of New Mexico, Albuquerque, \\ NM, USA
}

\begin{abstract}
Background and methods: Problems with the clinical management of prostate cancer include the lack of both specific detection and efficient therapeutic intervention. We report the encapsulation of superparamagnetic iron platinum nanoparticles (SIPPs) and paclitaxel in a mixture of polyethyleneglycolated, fluorescent, and biotin-functionalized phospholipids to create multifunctional SIPP-PTX micelles (SPMs) that were conjugated to an antibody against prostate-specific membrane antigen (PSMA) for the specific targeting, magnetic resonance imaging (MRI), and treatment of human prostate cancer xenografts in mice.

Results: SPMs were $45.4 \pm 24.9 \mathrm{~nm}$ in diameter and composed of $160.7 \pm 22.9 \mu \mathrm{g} / \mathrm{mL}$ iron, $247.0 \pm 33.4 \mu \mathrm{g} / \mathrm{mL}$ platinum, and $702.6 \pm 206.0 \mu \mathrm{g} / \mathrm{mL}$ paclitaxel. Drug release measurements showed that, at $37^{\circ} \mathrm{C}$, half of the paclitaxel was released in 30.2 hours in serum and two times faster in saline. Binding assays suggested that PSMA-targeted SPMs specifically bound to C4-2 human prostate cancer cells in vitro and released paclitaxel into the cells. In vitro, paclitaxel was 2.2 and 1.6 times more cytotoxic than SPMs to C4-2 cells at 24 and 48 hours of incubation, respectively. After 72 hours of incubation, paclitaxel and SPMs were equally cytotoxic. SPMs had MRI transverse relaxivities of $389 \pm 15.5 \mathrm{~Hz} / \mathrm{mM}$ iron, and SIPP micelles with and without drug caused MRI contrast enhancement in vivo.

Conclusion: Only PSMA-targeted SPMs and paclitaxel significantly prevented growth of C4-2 prostate cancer xenografts in nude mice. Furthermore, mice injected with PSMA-targeted SPMs showed significantly more paclitaxel and platinum in tumors, compared with nontargeted SPM-injected and paclitaxel-injected mice.
\end{abstract}

Keywords: iron platinum, MRI, prostate cancer, micelle, paclitaxel

\section{Introduction}

The continued prevalence and resistance to treatment of prostate cancer in the United States suggests that detection and therapeutic methods must be improved in order to combat this disease, especially in the deadly, advanced hormone-refractory stage. As of 2011, prostate cancer remained the most commonly detected male cancer in the United States and the second most common reason for cancer death in men. With over 200,000 newly diagnosed cases, and in excess of 30,000 mortalities, prostate cancer continues to be a major burden on the health and financial security of countless men and families. ${ }^{1,2}$ After a rapid increase in diagnosed cases in the $1990 \mathrm{~s}$, mostly due to prostate-specific antigen testing, the number of newly diagnosed cases has reached a plateau over the past few years. Numerous new therapies have entered clinical trials in 
recent years, without a meaningful decline in mortality rate, ${ }^{1-6}$ so innovative therapies continue to be required.

Over the past decade, significant progress has been made with respect to the development of novel nanoparticles designed for the detection or treatment of cancers. ${ }^{7-13}$ The most common types of nanoparticles used for the detection of cancer were fluorescent, radioactive, or superparamagnetic core nanoparticles which were rendered biocompatible by encapsulation with polymers or phospholipids. ${ }^{7,11,14,15}$ Similarly, chemotherapeutic drugs were added to the encapsulants with the expectation that more efficacious therapies, with reduced global toxicity, would result. ${ }^{16-18}$ These two types of nanoparticles are typically targeted to primary and/or metastatic tumors either passively by the enhanced permeability and retention effect, which relies on the leaky vasculature often found in tumors, or through active targeting of specifically overexpressed or highly expressed membrane antigens on the tumor cells or neovasculature. For this latter purpose, antibodies or peptides are often conjugated to the surface of the particles. ${ }^{19-21}$ The development of nanoparticles that combine these two functions, while highly desirable, has not received as much attention as that directed towards the synthesis of particles with separate functions.

Previously, superparamagnetic iron oxide nanoparticles (SPIONs) have been used as experimental magnetic resonance imaging (MRI) contrast agents to detect cancers. $^{22-25}$ In fact, two SPION contrast agents, Resovist ${ }^{\circledR}$ and Feridex ${ }^{\circledR}$, have been approved for use by the Food and Drug Administration. ${ }^{25,26}$ Although SPIONs produce contrast enhancement in MRI, the signal enhancement is often weaker than that found in radioisotopic imaging modes, such as positron emission tomography. ${ }^{27}$ Therefore, better MRI contrast agents are urgently needed in order to increase signal enhancement for the noninvasive detection of cancer. We have previously reported that superparamagnetic iron platinum nanoparticles (SIPPs) are superior MRI contrast agents compared with the more commonly used SPIONs. ${ }^{28,29}$ For this reason, we chose to use SIPPs as our core magnetic particle for MRI. Additionally, we previously showed that these SIPP particles could be encapsulated into micelles using a mixture of PEGylated phospholipids and that these particles could be specifically targeted to prostate cancer cell lines, in vitro, using an anti-prostate-specific membrane antigen (PSMA) antibody. ${ }^{29}$

Here, we report the synthesis, characterization, and application of specifically-targeted, multifunctional SIPPs ${ }^{28}$ encapsulated in a mixture of phospholipids and combined with the drug, paclitaxel. These SIPP-PTX micelles (SPMs) were subsequently conjugated to a humanized monoclonal antibody (J591) against PSMA to produce targeted SPMs for the combined MRI and therapy of prostate cancer. We measured the physical, magnetic, binding, and cytotoxic properties of the particles in vitro, and the MRI contrast enhancement, biodistribution, and efficacy in vivo were compared with controls.

\section{Materials and methods Materials}

Iron nitrate nonahydrate $\left(\mathrm{Fe}\left(\mathrm{NO}_{3}\right)_{3} \cdot 9 \mathrm{H}_{2} \mathrm{O}\right)$, platinum (II) acetylacetonate $\left(\mathrm{Pt}(\mathrm{Acac})_{2}\right)$, and 1-octadecylamine were purchased from Fisher Scientific (Pittsburgh, PA). The phospholipids:1,2-distearoyl-sn-glycero-3phosphoethanolamine-N-[amino- (polyethyleneglycol)2000] (DSPE-PEG), DSPE-PEG with biotin conjugated to the head group (biotin-DSPE-PEG), and 1,2-dimyristoyl-snglycero-3-phosphoethanolamine-N-[lissamine rhodamine B sulfonyl] (Liss-Rhod) were purchased from Avanti Polar Lipids (Alabaster, AL). The C4-2 human prostate cancer cell line was a generous gift from Marco Bisoffi (UNM Cancer Center, University of New Mexico). All other chemicals and supplies were purchased from common manufacturers.

\section{Synthesis of SIPP cores}

One mmol of $\mathrm{Fe}\left(\mathrm{NO}_{3}\right)_{3} \cdot 9 \mathrm{H}_{2} \mathrm{O}$ and $1.0 \mathrm{mmol}$ of $\mathrm{Pt}(\mathrm{Acac})_{2}$ were added to $12.5 \mathrm{mmol}$ of 1-octadecylamine in a $25 \mathrm{~mL}$, threeneck, round-bottomed flask fitted with a reflux condenser. The mixture was heated to $330^{\circ} \mathrm{C}$ (at a rate of $200^{\circ} \mathrm{C}$ per hour) with $10^{\circ} \mathrm{C}$ recirculated cooling in the reflux condenser. Refluxing was continued for an additional 45 minutes, at which point the reaction was allowed to cool to room temperature. The resulting black particles were collected in hexane and subjected to repeated washing before resuspending in hexane.

\section{Encapsulation of SIPP cores and paclitaxel} Phospholipid-encapsulated SIPP cores with and without paclitaxel (SPMs and SMs, respectively) were prepared using a thin film method. Then, $0.5 \mathrm{~mL}$ of SIPP cores ( $1.4 \%$ solids $)$ in hexane was added to a $20.0 \mathrm{~mL}$ glass scintillation vial. A chloroform mixture of (56:1:1 mole ratio) DSPE-PEG, biotin-DSPE-PEG, and Liss-Rhod was then added to the SIPP cores. In the SPM preparations, $0.4 \mathrm{~mL}$ of $8 \mathrm{mg} / \mathrm{mL}$ paclitaxel in chloroform was also added to the reaction. In the SPM preparations used for confocal binding experiments, $1.0 \mu \mathrm{g}$ of Oregon Green ${ }^{\circledR}$ 488-paclitaxel conjugate (Invitrogen, Eugene, OR) was added to the mixture. The mixture was 
further diluted in $0.5 \mathrm{~mL}$ of methanol and vortexed. The mixture was evaporated under a nitrogen stream to produce the thin film. Next, $5.0 \mathrm{~mL}$ of double-distilled water was heated to $90^{\circ} \mathrm{C}$ and added to the thin film. Hydration was immediate upon vortexing. The hydrated particles were then extruded at $67^{\circ} \mathrm{C}$ through an $80 \mathrm{~nm}$ Nucleopore track-etch membrane filter using a mini-extruder (Avanti Polar Lipids) to produce micelles of approximately $45 \mathrm{~nm}$. The SPMs and SMs were then purified from SIPP-free micelles, excess phospholipids, and drug by collecting the particles using an LS magnetic column placed in a VarioMACS ${ }^{\text {TM }}$ magnetic separator (Miltenyi Biotec, Carlsbad, CA). After the nonmagnetic material had passed through the column, $8.0 \mathrm{~mL}$ of double-distilled water was added to wash the particles. The column was removed from the magnet and $1.0 \mathrm{~mL}$ of sterile saline was used to elute the purified SPMs and SMs. For SPMs and SMs for injections into mice, the eluted particles were applied to smaller $(0.5 \mathrm{~mL})$ microcolumns (Miltenyi Biotec) and eluted with 200-300 $\mu \mathrm{L}$ of sterile saline.

\section{Physical characterization of SPMs}

Transmission electron microscopy (TEM) was used to determine the size and polydispersity of the particle populations. For SIPPs, a $10 \mu \mathrm{L}$ drop of particles was applied to a carbon-coated grid and allowed to dry. For SPMs and SMs, a $10 \mu \mathrm{L}$ drop of the aqueous suspension was applied to a carbon-coated grid and allowed to dry for 10 minutes. Adding $5 \mu \mathrm{L}$ of $2 \%$ uranyl acetate negatively stained the grid. The samples were imaged using Hitachi 7500 TEM with an acceleration voltage of $80 \mathrm{kV}$. Particle diameters were calculated using Image J Software. ${ }^{30}$ At least 100 particles were counted and the mean Feret's diameters and standard deviations were calculated. Diameters of the SPMs were additionally measured using dynamic light scattering with a Microtrac Nanotrac ${ }^{\mathrm{TM}}$ Ultra device (Microtrac, Largo, FL). Inductively coupled plasma-optical emission spectroscopy (ICP) was used to measure the metal content of each synthesis. Prior to analysis, aliquots of the particles were digested at $180^{\circ} \mathrm{C}$ with nitric acid and hydrochloric acid in a PDS-6 pressure digestion system (Loftfields Analytical Solutions, Neu Eichenberg, Germany). After cooling, the samples were made up to a known volume, mixed, and centrifuged. Samples were then analyzed using a PerkinElmer Optima 5300DV ICP. The recommended wavelengths for each of the analytes were used, and a blank set of calibration standards were used to establish a three-point calibration curve. Calibration and instrument verification samples were analyzed before and after analyzing the samples, as well as periodically throughout the measurements. Analyte peaks were examined and peak identification and background points were adjusted for optimum recoveries.

\section{Magnetic resonance relaxometry}

Increasing concentrations of SPMs (0-400 $\mu \mathrm{M}$ iron) were added to $1 \%$ agarose in $2.0 \mathrm{~mL}$ self-standing microcentrifuge tubes (Corning, Corning, NY). Samples were imaged on a 4.7 Tesla Bruker Biospin (Billerica, MA) MRI system with Paravision 4.0 software. Samples were imaged with a $512 \times 256$ matrix, a variable echo time, and repetition time of 10 seconds. $T_{1}$ measurements were acquired by inversion recovery with 15 interpulse delays. Spin-echo and gradient-echo sequences were used to measure $\mathrm{T}_{2}$ and $\mathrm{T}_{2}{ }^{*}$, respectively. The MRI samples were then analyzed as above to determine the iron concentration using ICP. The relaxation rates, $R_{n}=1 / T_{n}$, were calculated and plotted versus the ICPdetermined iron concentration of each sample. The relaxivity $\left(r_{n}\right)$ of each sample is given as the slope of the linear regression line in units of $\mathrm{s}^{-1} \mathrm{mM}^{-1}(\mathrm{~Hz} / \mathrm{mM})$ of iron.

\section{Drug-loading capacity and drug release rates}

The amount of paclitaxel loaded into the particles was quantitated using a competitive enzyme-linked immunosorbent assay (Cardax Pharmaceuticals, Aiea, HI), according to the manufacturer's instructions. Briefly, a $100 \mu \mathrm{L}$ aliquot of SPMs was added to $200 \mu \mathrm{L}$ of a 1:1 (vol/vol) acetonitrile:methanol mixture. The mixture was incubated with occasional vortexing. After 30 minutes, the solution was centrifuged at 14,000 rpm for 5 minutes. Ten-fold dilutions of the supernatant were prepared in phosphate-buffered saline containing methanol. Next, $50 \mu \mathrm{L}$ of each dilution was used in the enzyme-linked immunosorbent assay, in triplicate, to determine the amount of paclitaxel loaded into the particles. For the drug release rate experiments, a $100 \mu \mathrm{L}$ aliquot of freshly prepared particles (approximately $1.0 \mathrm{~mL}$ ) was collected as the zero-hour time point. At various subsequent time points, the particles were collected on a magnetic column placed in a VarioMACS ${ }^{\mathrm{TM}}$ magnetic separator. The nonmagnetic material flow through (released paclitaxel) was collected for enzyme-linked immunosorbent assay quantitation, and the collected particles were then eluted in the original volume of serum or saline; an aliquot of particles was then taken for the enzyme-linked immunosorbent assay, and the collected particles were incubated at $4^{\circ} \mathrm{C}, 20^{\circ} \mathrm{C}$, or $37^{\circ} \mathrm{C}$ until the next time point. This routine was repeated until the completion of the experiment. As above, particles were added to an equal volume of acetonitrile:methanol prior 
to the enzyme-linked immunosorbent assay. The amount of paclitaxel in each well was measured based on a baccatin IIIprotein standard curve.

\section{Antibody conjugation, cell culture, and confocal binding assay}

J591 (purchased from Neal Bander, Cornell College of Medicine) and polyclonal goat antirabbit IgG (Sigma, St Louis, MO) were conjugated to streptavidin using a Lightning-Link ${ }^{\mathrm{TM}}$ streptavidin conjugation kit (Innova Biosciences, Cambridge, UK). Concentrations of streptavidin, antibodies, and streptavidin-antibody conjugates were quantitated using a NanoDrop ${ }^{\text {TM }} 2000$ spectrophotometer (Wilmington, DE). Briefly, the antibody alone (unconjugated) was measured at $280 \mathrm{~nm}$ using the nanoDrop spectrophotometer. After conjugating the streptavidin to the antibody, the conjugated antibody was again measured at $280 \mathrm{~nm}$. Using the molecular weights of antibody and streptavidin and the increase in protein concentration measured at 280 after conjugation, we then calculated the amount of streptavidin conjugated to the antibody. Streptavidinconjugated antibodies (about $1.0 \mu \mathrm{g}$ ) were then incubated with SPMs or SMs (about $150 \mu \mathrm{g}$ iron) at $4^{\circ} \mathrm{C}$ to conjugate the antibodies to the SIPP micelles through the biotin groups of the biotin-DSPE-PEG. Briefly, after conjugating the antibodies to the iron platinum micelles, the magnetic nanoparticles were collected (purified away from unbound antibody) using a magnetic column. The flow through (containing unbound antibody) was then collected. The particles were washed three times with water and then eluted from the column with sterile saline. The amount of unbound antibody in the flow through was quantified using a micro $\mathrm{BCA}^{\mathrm{TM}}$ protein assay (Thermo Scientific, Rockford, IL) and a BioSpec-mini spectrophotometer (Shimadzu, Columbia, MD) at a wavelength of $562 \mathrm{~nm}$. The difference in the amount of antibody added to the micelles minus the amount of antibody in the flow through was then determined to be the amount of antibody conjugated to the micelles. For binding experiments utilizing confocal microscopy, 20,000 C4-2 human prostate cancer cells in RPMI 1640 medium containing 10\% fetal bovine serum and $100 \mathrm{U} / \mathrm{mL}$ penicillin-streptomycin solution were seeded onto polylysine-coated cover slips in 6-well polystyrene plates (Corning) and incubated at $37^{\circ} \mathrm{C}$ with $5 \% \mathrm{CO}_{2}$ for 24 hours. The medium was then exchanged with medium containing J591-SPMs (about $4.0 \mu \mathrm{g}$ iron), IgG-SPMs (about $4.0 \mu \mathrm{g}$ iron), or phosphate-buffered saline $(40 \mu \mathrm{L})$. The SPMs for the binding experiments were prepared by doping with green fluorescent paclitaxel (Invitrogen) prior to encapsulation.
The cells were incubated with the particles for 10 minutes at $4^{\circ} \mathrm{C}$, the media were aspirated off, and $5.0 \mathrm{~mL}$ phosphatebuffered saline was added to wash the unbound particles away from the cells. Washing was repeated three times. Cover slips were mounted on slides containing a drop of ProLong ${ }^{\circledR}$ Gold Antifade Reagent with DAPI (Invitrogen). Confocal images were acquired using an Olympus DSU spinning disk confocal microscope in the University of New Mexico and Cancer Center Fluorescence Microscopy Shared Resource.

\section{Cytotoxicity}

Five thousand C4-2 cells in $100 \mu \mathrm{L}$ of RPMI 1640 medium were cultured in 96-well plates. The following day, media were exchanged with $100 \mu \mathrm{L}$ of media containing the treatment or controls in increasing concentrations of paclitaxel and platinum, determined by measuring the paclitaxel and platinum content of the preparations using the paclitaxel enzyme-linked immunosorbent assay and ICP, respectively (see earlier). A WST-1 cytotoxicity kit was used to quantitate the number of metabolically active cells at 24,48 , or 72 hours. The absorbencies of the samples were normalized to the no-treatment control. Dose-response curves were generated as a function of increasing concentration of treatments/ controls. The dose to inhibit the metabolic activity of 50\% of the cells was then determined.

\section{Animal experiments}

The University of New Mexico International Animal Care and Use Committee approved all experiments involving animals. Athymic nude mice had $3 \times 10^{6} \mathrm{C} 4-2$ human prostate cancer cells in $50 \%$ (vol/vol) Matrigel ${ }^{\circledR}$ (BD Bioscience, Bedford, MA) subcutaneously injected into the right flank. The mice were monitored, and the length, width, and height of the tumors were measured using a digital caliper. The volumes of the xenografts were determined using the equation $V=(4 / 3) a b c$, where $\mathrm{V}$ is the tumor volume and $\mathrm{a}, \mathrm{b}$, and $\mathrm{c}$ are half the length, width, and height, respectively. Once xenografts had reached volumes of about $75 \mathrm{~mm}^{3}$, the mice were subjected to MRI and injections of either treatments or controls.

\section{In vivo $M R I$ and injections}

Once the xenografts had reached the appropriate volume, the mice were anesthetized using a nose cone that delivered an isoflurane and oxygen mixture and imaged on a 4.7 Tesla Bruker Biospin MRI system with Paravision 4.0 software. Mice were imaged with a $256 \times 256$ pixel matrix with $156 \mu \mathrm{m}$ pixels and a $40 \mathrm{~mm}$ field of view. $\mathrm{T}_{1}$ measurements were 
acquired with a echo time of $14 \mathrm{msec}$ and a rapid acquisition with relaxation enhancement with variable repetition time sequence. $T_{2}$ measurements were acquired with an echo time of $12 \mathrm{msec}$ and a multi-slice multi-echo sequence. After preinjection imaging, the mice were injected retro-orbitally with $150 \mu \mathrm{L}$ of of either treatments or controls. Injections contained approximately $200 \mu \mathrm{g}$ of iron (SPMs and SMs) and $702.6 \pm 206 \mu \mathrm{g}$ of paclitaxel (SPMs). The paclitaxel-only mice were injected with $400 \mu \mathrm{g}$ of paclitaxel in a total volume of $150 \mu \mathrm{L}$ of castor oil and saline. Additionally, some mice were not injected as a "no-injection" control group. After the preinjection imaging and subsequent injections, the mice were imaged at various time points ranging from 15 minutes to 24 hours following injection. The $T_{1}$ and $T_{2}$ images were analyzed using Image J. ${ }^{30}$ Regions of interest in the tumor and muscle were selected and the mean pixel intensity was recorded. Contrast was then calculated as $C=\left(I_{t}-I_{m} / I_{m}\right)$, where $C$ is the contrast and $\mathrm{I}_{t}$ and $\mathrm{I}_{m}$ are the pixel intensity in the tumor or muscle, respectively. The contrast was normalized to the preinjection images to produce the contrast (\%), calculated as $C \%=\left(C_{t} / C_{o}\right) \times 100$, where $C_{t}$ and $C_{o}$ are the contrast of the tumor at the time point and initial contrast of the tumor in the preinjection image, respectively. Contrast (\%) was then plotted versus time after injection.

\section{Biodistribution and therapeutic efficacy}

Mice were monitored for 20 days following injection with either treatments or controls. The tumor volumes were measured weekly and mice were monitored for adverse reactions. On day 20 following injection, the mice were euthanized using asphyxiation with carbon dioxide, and the tumor and organs were collected and weighed. Portions of the tumor and organs were then sectioned and again weighed for ICP and analysis of platinum and paclitaxel content, respectively. The amounts of platinum and paclitaxel were calculated as percent of the platinum or paclitaxel in the original injection. The average and standard deviation of platinum and paclitaxel in each group of mice was then calculated and plotted for each tissue or xenograft to determine the biodistribution and percent targeting. Tumor volumes were compared between each of the groups of mice. Efficacy was measured by decreases in tumor volume in the treatment versus control groups.

\section{Results}

\section{Size and composition of SPMs}

Figure 1 shows a TEM image of the SPMs, which had diameters of $45 \pm 25 \mathrm{~nm}$ as determined using dynamic light scattering. This large standard deviation was representative

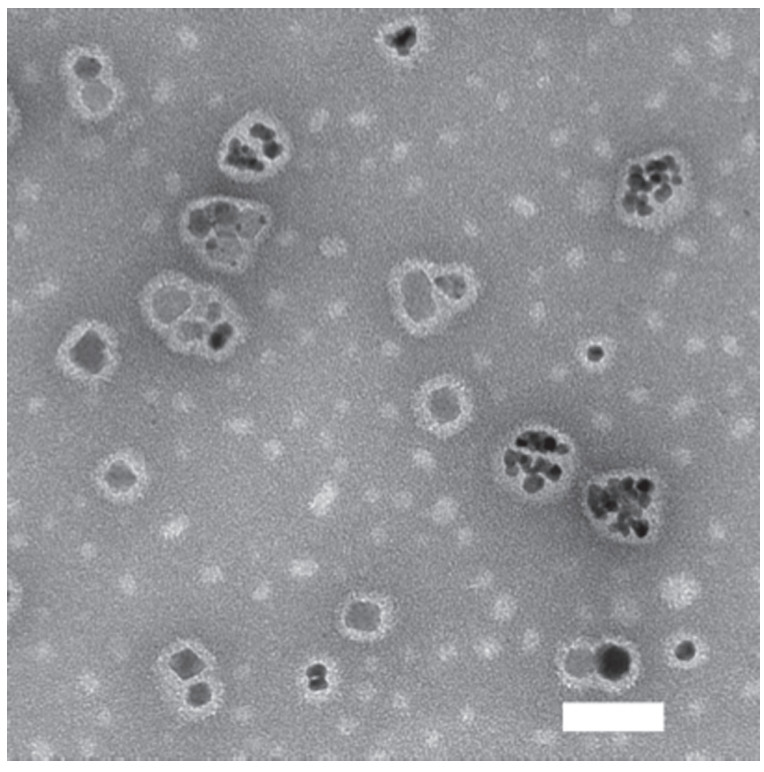

Figure I Transmission electron microscopic image of SPMs.

Notes: SPMs were applied to a carbon-coated grid and allowed to dry. Adding a drop of $2 \%$ uranyl acetate negatively stained the grid. The samples were imaged on an Hitachi 7500 transmission electron microscope with an acceleration voltage of $80 \mathrm{kV}$. The scale bar is $50 \mathrm{~nm}$.

Abbreviation: SPMs, superparamagnetic iron platinum nanoparticles and paclitaxel in a mixture of PEGylated and biotin-functionalized phospholipids.

of the polydispersity that can be seen in the TEM image (Figure 1). The SPMs appeared to fall into two morphological groups. One group had multiple, approximately $9 \mathrm{~nm}$ diameter SIPPs (in agreement with our earlier data ${ }^{23,30}$ ) encapsulated in the core and were larger in overall diameter (about $50 \mathrm{~nm}$ ), whereas the other group of particles had smaller diameters of $29 \pm 2 \mathrm{~nm}$, and appeared to contain only a single $17 \pm 2 \mathrm{~nm}$ SIPP core encapsulated in the center. It is important to note that all particles were first purified with a magnetic column; this fact implies that all of the particles in the TEM image possessed a magnetic SIPP core. It is possible that the smaller micelles resulted from a reaction between the FePt alloy and paclitaxel, which generated a crystalline complex between the drug and the alloy. The metal content of the SPMs was determined using ICP. We compared seven separate preparations of SPMs and found that they contained $161 \pm 23 \mu \mathrm{g} / \mathrm{mL}$ of iron, $247 \pm 33 \mu \mathrm{g} / \mathrm{mL}$ of platinum, and an iron to platinum stoichiometry of $2.3 \pm 0.4$, suggesting that our method of making SPMs provided good reproducibility.

\section{Magnetic relaxivities of micelles}

We next compared the relaxivities of micelles with and without drug using magnetic resonance relaxometry. As expected from our previous characterizations of SIPP cores, ${ }^{28,29}$ SIPP micelles without paclitaxel (SMs) and SPMs had high transverse relaxivities of $r_{2}=300 \pm 12$ and $389 \pm 16 \mathrm{~Hz} / \mathrm{mM}$ 
iron, respectively, making them superior contrast agents for $\mathrm{T}_{2}$-weighted MRI, compared with SPIONs that generally have transverse relaxivities between 30 and $180 \mathrm{~Hz} / \mathrm{mM}$ iron. ${ }^{31-34}$

\section{Paclitaxel loading of micelles}

The amount of paclitaxel encapsulated in the SPM preparations (drug-loading capacity) was determined using a paclitaxel enzyme-linked immunosorbent assay. The average drug-loading capacity for seven preparations of particles was $703 \pm 206 \mu \mathrm{g} / \mathrm{mL}$ paclitaxel. The high standard deviation suggests that the amount of paclitaxel incorporated into the micelles was subject to some unknown variation, perhaps due to phase fractionation, and that other methods of incorporating the drug into the particles, such as anchoring the drug to the micelles by conjugating a lipid chain to the drug, may be useful in the future.

\section{Paclitaxel release from micelles}

We next aimed to measure how fast the drug was released from the micelles (drug release rate) in different solutions and at different temperatures. Figure 2 shows the drug release rates for the particles in serum and saline at $4^{\circ} \mathrm{C}$ and $37^{\circ} \mathrm{C}$. The time at which half of the paclitaxel had been released from the particles $\left(\mathrm{R}_{0.5}\right)$ under the different conditions was 19.4 and 14.0 hours for SPMs in saline at $20^{\circ} \mathrm{C}$ and $37^{\circ} \mathrm{C}$, respectively. In contrast, the SPMs in serum at $4^{\circ} \mathrm{C}$ and $37^{\circ} \mathrm{C}$ had $\mathrm{R}_{0.5}$ times of 38.9 and 30.2 hours, respectively.

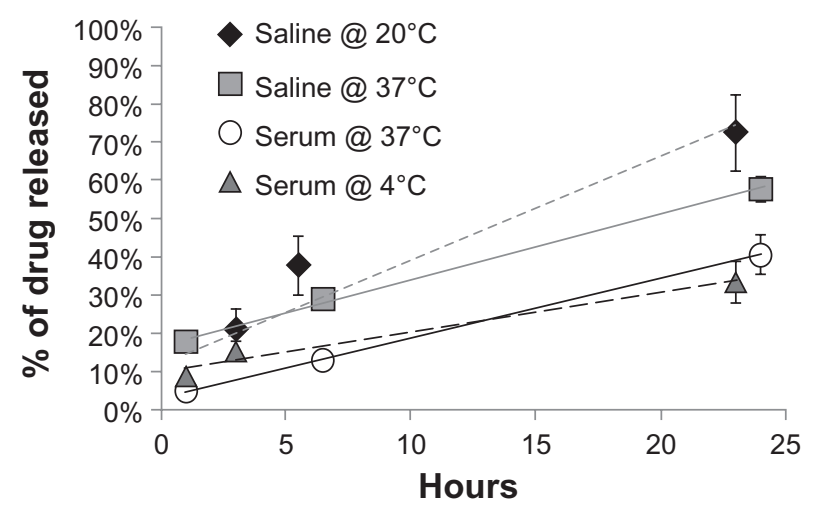

Figure 2 Temperature dependence of drug release rates for SPMs in serum and saline. Notes: A $100 \mu \mathrm{L}$ aliquot of freshly prepared particles was collected as the zerohour time point. At subsequent time points, the particles were magnetically retained on a column and the amount of paclitaxel in the nonmagnetic flow-through and in the magnetic particles was measured using an enzyme-linked immunosorbent assay. The amount of drug release is shown as the percentage of drug released compared with the initial amount of drug loaded into the particles, as measured with enzymelinked immunosorbent assay immediately after encapsulation. SPMs were incubated in saline at $20^{\circ} \mathrm{C}$ (diamonds), saline at $37^{\circ} \mathrm{C}$ (squares), serum at $37^{\circ} \mathrm{C}$ (circles), or serum at $4^{\circ} \mathrm{C}$ (triangles).

Abbreviation: SPMs, superparamagnetic iron platinum nanoparticles and paclitaxel in a mixture of PEGylated and biotin-functionalized phospholipids.
It was clear that the drug was released half as fast in serum ( $\mathrm{R}_{0.5}$ about 30 hours) than in saline $\left(\mathrm{R}_{0.5}\right.$ about 14 hours) at $37^{\circ} \mathrm{C}$. It has previously been suggested that drugs were released at different rates from nanoparticles in the presence of different serum proteins $\mathrm{s}^{35-37}$ and, therefore, it is possible that serum proteins may have been binding to our SPMs to some extent, causing the drug to be released more slowly due to an increase in the hydrodynamic diameter of the micelles when protein-bound. An interesting future study would be to determine which proteins and to what extent these proteins bind to our PEGylated micelles.

\section{Specific binding of antibody-conjugated micelles to prostate tumor cells}

We conjugated J591, raised against the extracellular portion of PSMA, to our SPMs and measured the specific binding of the J591-SPMs to C4-2 human prostate cancer cells that express over one million PSMA receptors on the cell surface. ${ }^{38}$ Figure 3 shows that, compared with C4-2 cells incubated with nontargeted IgG-SPM micelles, PSMAtargeted J591-SPMs bound specifically to C4-2 cells. Also of importance is that fluorescent paclitaxel can also be seen inside C4-2 cells that were specifically targeted and not in the cells that were incubated with IgG-SPMs, suggesting not only specific delivery of the contrast agent, but also specific intracellular delivery of the drug.

\section{Cytotoxicity comparison of SPMs versus paclitaxel}

Because the above results showed that SPMs specifically bound to and were taken up by prostate cancer cells, it was of interest to determine if this intracellular delivery of paclitaxel was cytotoxic to C4-2 cells and to compare the cytotoxicity of the SPMs with that of the SMs. Figure 4 shows the cytotoxicity measurements for our SIPP micelles with and without drug over the course of 72 hours. The intracellular delivery of paclitaxel by the SPMs was equally cytotoxic to the cells compared with paclitaxel alone after 72 hours of incubation. However, paclitaxel alone was somewhat more cytotoxic at 24 and 48 hours compared with SPMs; the drug concentration needed to inhibit $50 \%$ of the metabolic activity of the cells $\left(\mathrm{IC}_{50}\right)$ at 24 hours was $22 \mu \mathrm{M}$ and $50 \mu \mathrm{M}$ for paclitaxel alone and SPMs, respectively. At 48 hours, the $\mathrm{IC}_{50 \mathrm{~s}}$ for paclitaxel and SPMs were $17 \mu \mathrm{M}$ and $28 \mu \mathrm{M}$ drug. In comparison, by 72 hours, both paclitaxel and SPMs had the same $\mathrm{IC}_{50}$ of $0.1 \mu \mathrm{M}$ drug. Thus, in vitro, paclitaxel was 2.2 and 1.6 times more cytotoxic to C4-2 cells at 24 and 48 hours, respectively, but were equally cytotoxic at 


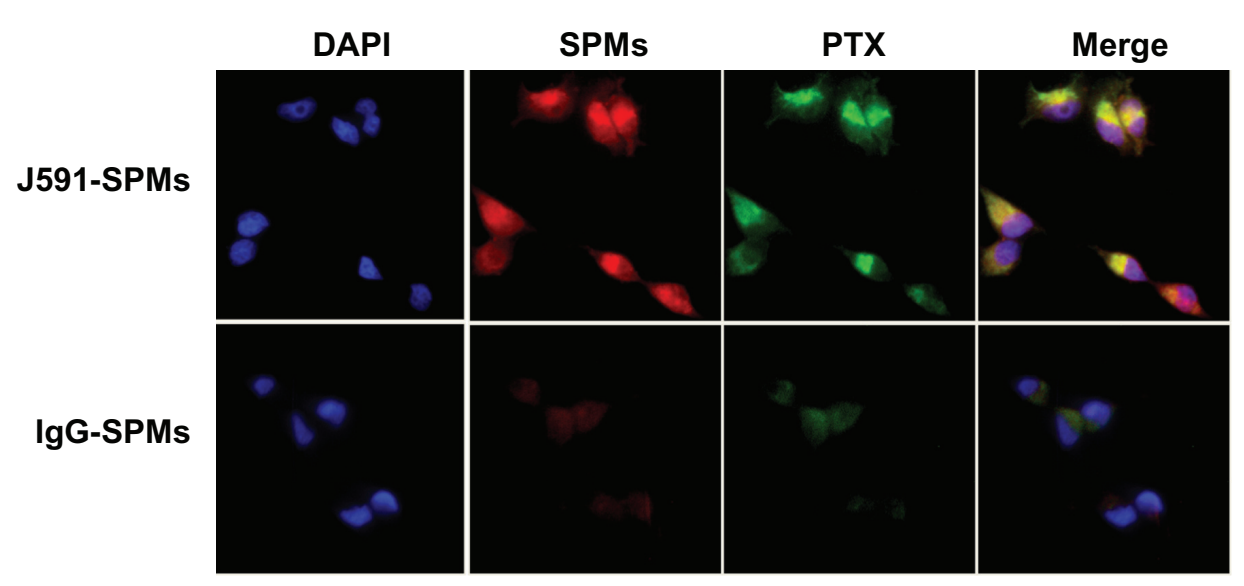

Figure 3 Specific binding of J59I-SPMs to C4-2 prostate cancer cells.

Notes: Confocal images of PSMA-targeted, rhodamine red-containing SPMs containing fluorescent paclitaxel (green, top row) and control lgG-SPMs (bottom row) incubated with C4-2 human prostate cancer cells and stained with DAPI. The last column on the right shows the summed images, which display all three colors for the J59I-SPMs, and only shows DAPI staining for the IgG-SPMs.

Abbreviations: PSMA, prostate-specific membrane antigen; SPMs, superparamagnetic iron platinum nanoparticles and paclitaxel in a mixture of PEGylated and biotinfunctionalized phospholipids.

72 hours. This difference is most likely due to the fact that it takes about 30 hours for the drug encapsulated in the SPMs to escape (Figure 2). The SIPP micelles in the absence of drug were not found to be cytotoxic to the C4-2 cell line (Figure 4D) using platinum concentrations that were in the same range as those used in the SPM cytotoxicity experiments.
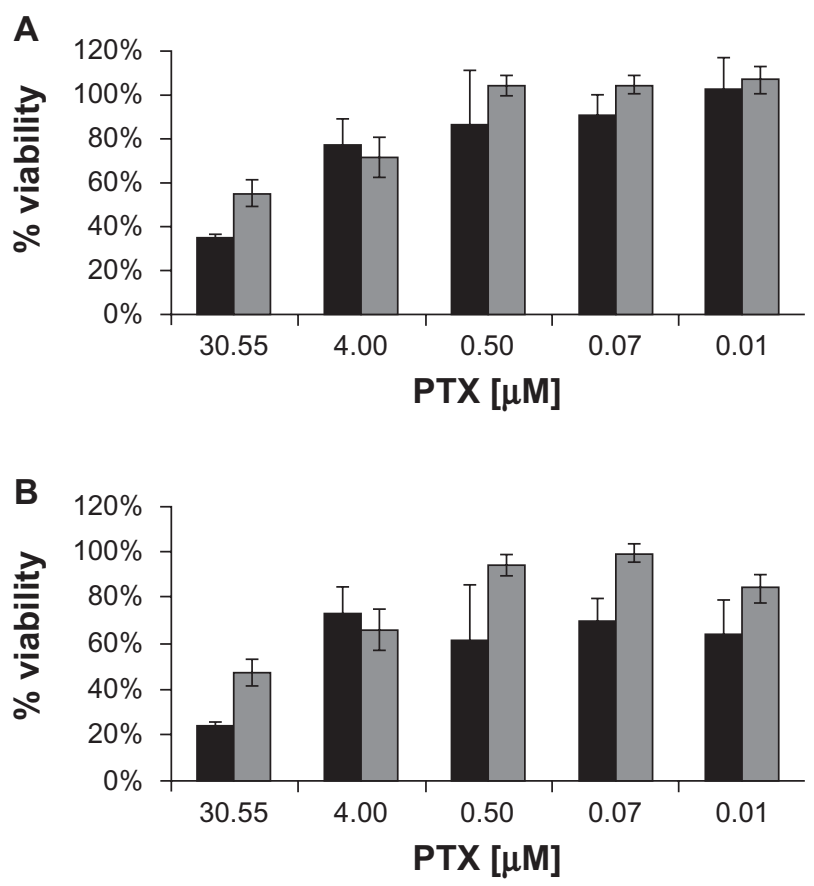

\section{SPMs and SIPPs as MRI contrast agents}

We next produced C4-2 human prostate cancer xenografts in nude mice and performed MR imaging of the tumor both before and after injection of the treatments or controls. Figure 5 shows the $\mathrm{T}_{1}$ - and $\mathrm{T}_{2}$-contrast enhancements measured in the tumors as a function of time, with representative images of an SPM-injected tumor. The J591-SPMs
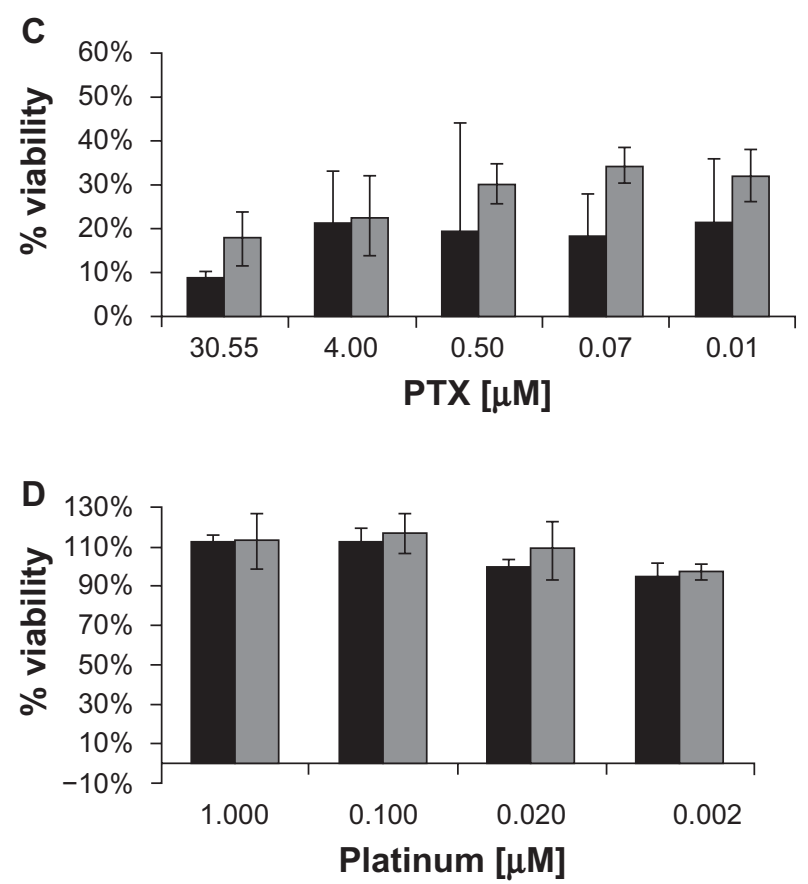

Figure 4 Cytotoxicity measurements of paclitaxel, SPMs, and SMs in C4-2 prostate cancer cells. The graphs show C4-2 cell viability measured with a WST-I assay after incubation with paclitaxel or SPMs for (A) 24 hours, (B) 48 hours, and (C) 72 hours. Viability after incubation with SPMs (gray bars) and paclitaxel (black bars) is shown as the percentage of viable cells compared with control samples not incubated with particles or drug. (D) Image showing the lack of cytotoxicity when C4-2 human prostate cancer cells are incubated with SIPP micelles without drug (SMs) for 24 hours (black bars) and 48 hours (gray bars).

Abbreviations: SIPP, superparamagnetic iron platinum nanoparticle; SMs, superparamagnetic iron platinum nanoparticle micelles without drug; SPMs, superparamagnetic iron platinum nanoparticles and paclitaxel in a mixture of PEGylated and biotin-functionalized phospholipids. 

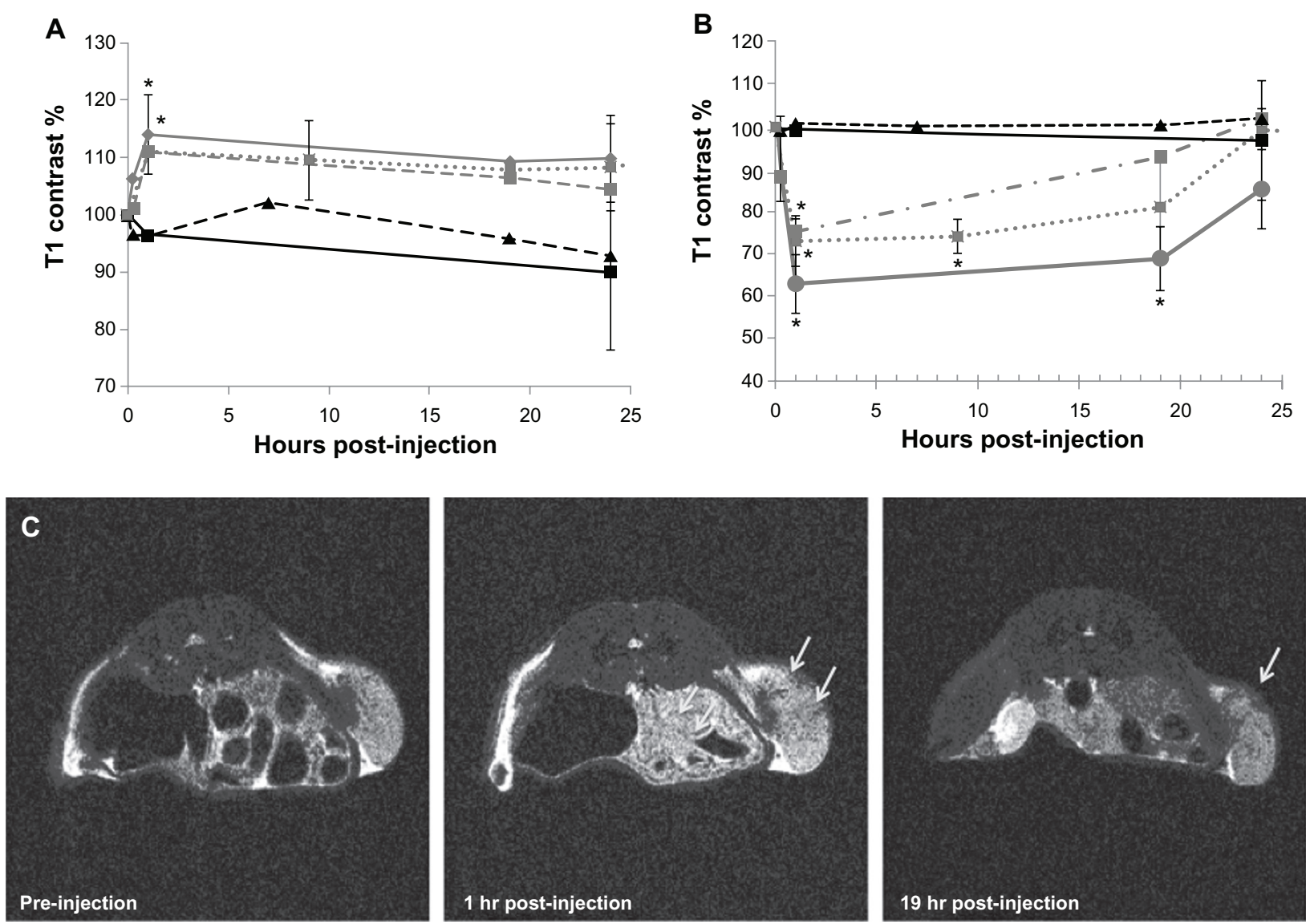

Figure 5 In vivo magnetic resonance imaging and contrast measurements of a mouse bearing a C4-2 xenograft. Longitudinal (A) and transverse (B) contrast percentage measured for mice bearing C4-2 xenografts and injected with either J59I-SPMs (diamond, solid gray line), J59I-SMs (square, dotted gray line), IgG-SPMs (square, dashed gray line), paclitaxel only (triangle, dashed black line), or nothing (square, solid black line). Representative $\mathrm{T}_{2}$-weighted magnetic resonance images of a mouse injected with J59I-SPMs are shown in (C).

Notes: The arrows point to areas in the C4-2 xenograft that showed dark contrast enhancement at one hour following injection in the middle frame and an area that still showed contrast enhancement 19 hours after injection in the far right frame. $* p<0.05$.

Abbreviations: SMs, superparamagnetic iron platinum nanoparticle micelles without drug; SPMs, superparamagnetic iron platinum nanoparticles and paclitaxel in a mixture of PEGylated and biotin-functionalized phospholipids.

and IgG-SPMs, as well as J591-SMs, all showed contrast enhancement in $\mathrm{T}_{1}$-weighted and $\mathrm{T}_{2}$-weighted MR images of the tumors after injection. The $\mathrm{T}_{2}$-contrast was more pronounced and retained in tumors targeted with J591SPMs and J591-SMs, whereas contrast enhancement in the tumors of mice injected with nontargeted IgG-SPMs was lost more quickly. Significant $\mathrm{T}_{2}$-contrast at 19 hours following injection was only measured with J591-targeted micelles.

\section{Xenograft growth inhibition by SPMs}

The tumor volumes of the mice were measured over time. The data in Figure 6 show that only the J591-SPMs and paclitaxel were able to prevent growth of tumors in the mice significantly. The nontargeted IgG-SPMs did not significantly reduce the tumor burden in the animals, nor did the J591-SMs. None of the mice in the treatment or control groups showed significant differences in tissue weight or overall body weight over the course of the experiment (Supplemental Figures 1 and 2). In contrast with the J591-SPM injected mice that showed no adverse effects of the treatment, paclitaxel-injected mice suffered from severe hemorrhaging around the tumor (Supplemental Figure 3), two went blind, and one mouse was euthanized early due to neurological impairment.

Twenty days after injection of either treatments or controls, the mice were euthanized and the tumors and tissues were collected to quantify the paclitaxel and platinum in their tissues. From the data shown in Figure 7, it is evident that significantly more paclitaxel and platinum were found in the tumors of mice injected with J591-SPMs compared with mice injected with paclitaxel alone or IgG-SPMs. 


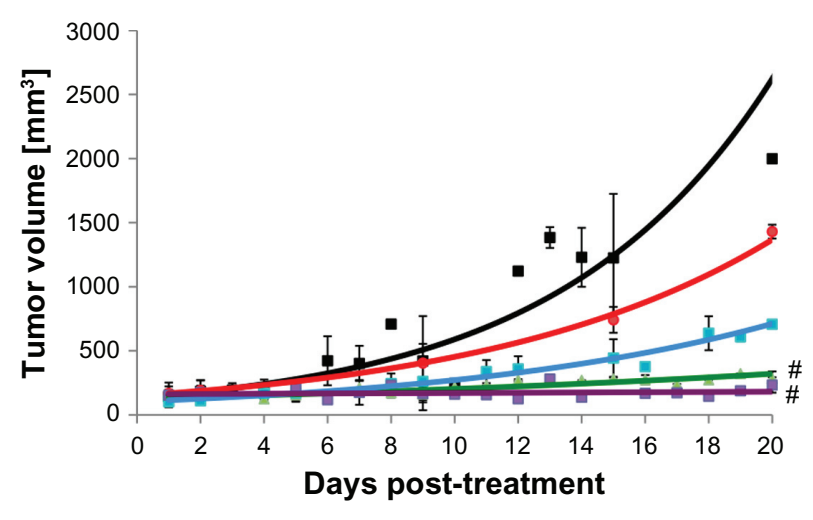

Figure 6 Tumor volume growth curves for nude mice bearing human C4-2 prostate cancer xenografts treated with various treatments or controls. (A) Black squares, no treatment controls. (B) Red squares, targeted SIPPs without drug, showing no effect on tumor growth. (C) Blue squares, SIPPs containing paclitaxel conjugated to a control IgG antibody, showing no effect on tumor growth. (D) Green triangles, paclitaxel alone, without SIPPs, showing the efficacy of this chemotherapeutic drug by itself. (E) Purple squares, SIPPs containing paclitaxel targeted to PSMA showing that targeting specifically brings the drug to the tumors and prevents tumor growth. Note: ${ }^{\sharp} P<0.05$.

Abbreviations: SIPPs, superparamagnetic iron platinum nanoparticles; PSMA, prostate-specific membrane antigen.

\section{Discussion}

Although SPIONs are the most common type of contrast agents used in contrast agent-enhanced MRI, nanoparticles with increased MRI relaxivities are needed in order to increase the contrast enhancement used for various medical conditions, including cancer. We have previously reported that SIPPs are superior contrast agents for MRI. ${ }^{28,29}$ The next important step was to determine if SIPPs could be beneficial as in vivo imaging agents and to measure any cytotoxicity of the particles. We have shown both in vitro (Figure 4) and in vivo (Supplemental Figures 1-3) that encapsulated iron platinum particles do not have any significant toxic effects on cells (over 48 hours) or mice (over 20 days). Platinum salts are known to be toxic, ${ }^{39-41}$ but the platinum in our particles was metallic and contained in a crystal structure alloyed with iron. Upon dissociation from the crystal, the platinum would still be metallic and not in the form of a salt. Platinum metal is chemically inert.

The biodistribution data (Supplemental Figure 4) for our SIPPs suggested that, in addition to being in the tumors, the platinum was primarily retained in the kidney, spleen, liver, and lungs. An important point when considering clinical application is that both platinum and paclitaxel were found in the feces of the mice 20 days following injection. This showed that the platinum and paclitaxel were excreted from the mice in their feces and, although a large percentage of both metal and drug was retained in the body 20 days after injection, the platinum and paclitaxel may eventually be eliminated. It would be of interest to perform biodistribution studies for at least a year to follow complete excretion.

Interestingly, both the J591-targeted micelles and the nontargeted IgG-micelle controls caused contrast enhancement in the tumors (Figure 5). Nonetheless, it was clear that the tumors of mice injected with J591-SPMs contained a higher concentration of both paclitaxel and platinum (Figure 5). This, in addition to the fact that the contrast enhancement in tumors of IgG-SPM injected mice was lost more quickly
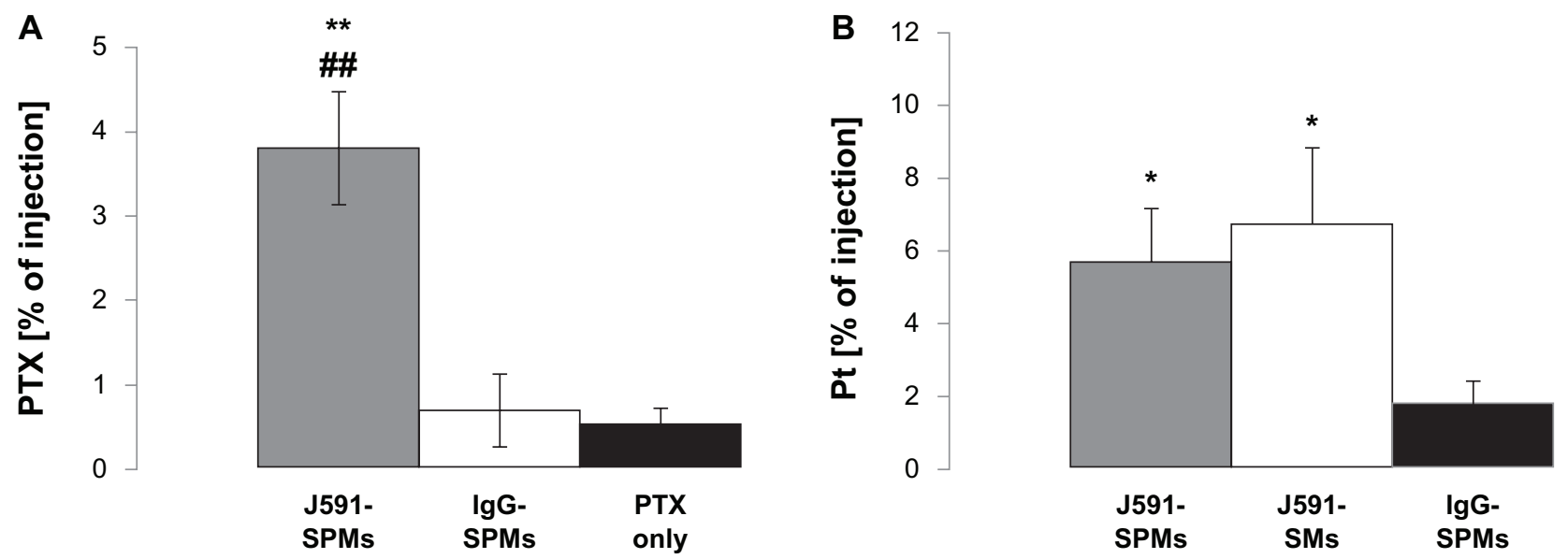

Figure 7 Tumor biodistribution of paclitaxel and platinum in mice bearing C4-2 xenografts and injected with treatments or controls. Mice were injected with paclitaxel alone (black bars), J59I-SPMs (gray bars), or lgG-SPMs (open bars) and 20 days after injection their tumors were collected and paclitaxel was measured as a percentage of the injected dose. Significantly more paclitaxel was measured in the tumors of mice injected with J59I-SPMs, compared with nontargeted SPMs and paclitaxel alone (A). Likewise, the biodistribution of platinum from the SIPPs in the mice injected with J59I-SPMs (gray bar), J59I-SMs (open bar), or IgG-SPMs (black bar) was measured, using ICP, as percent of the injected dose. Again, significantly more platinum was measured in the tumors of mice injected with J59I-SPMs, compared with nontargeted SPMs and paclitaxel alone (B).

Notes: ${ }^{* \# P}<0.05$ compared with paclitaxel alone or lgG-SPMs, respectively. ${ }^{* *}, \ldots 0.07$ compared with paclitaxel alone or lgG-SPMs, respectively.

Abbreviations: SMs, superparamagnetic iron platinum nanoparticle micelles without drug; SPMs, superparamagnetic iron platinum nanoparticles and paclitaxel in a mixture of PEGylated and biotin-functionalized phospholipids. 
in comparison with mice treated with J591-SPM (Figure 5), suggests that the enhanced permeability and retention effect is adequate for bringing the contrast agent into the tumor for MR imaging. In contrast, the data in Figure 6 show that mice injected with IgG-SPM did not have a therapeutic response to nontargeted treatment. This suggests that although the concentration of micelles in the tumors was high enough to generate MRI contrast enhancement due to the enhanced permeability and retention effect, it did not lead to accumulation of enough micelles to prevent tumor growth over time. It is also possible that the IgG-SPMs were not endocytosed and, therefore, the drug did not cause cell death because it did not reach the cytoplasm. Paclitaxel is a microtubule stabilizer that inhibits cell division, leading to cell death. ${ }^{42}$ The confocal images in Figure 3 show that only the J591-SPMs were internalized into the C4-2 cells in vitro, whereas the IgG-SPMs were not. This strongly suggests that, in vivo, only the J591-targeted micelles were able to enter into the cells, where the drug was released.

In order to achieve MRI contrast, the particles must only be attached to the vasculature and/or cells of the tumor, but in order to cause cell death, the particles must actually have been taken up by the cells. This could explain some of the discrepancies seen in the literature relating to the question of whether or not active targeting works. ${ }^{43}$ Our data suggest that an important distinction should be made between whether the nanoparticles generated tumor contrast or were actually therapeutic. Importantly, growth of the human prostate cancer xenografts in the nude mice was only inhibited in mice treated with paclitaxel or J591-SPMs. In contrast with the mice injected with paclitaxel (Supplemental Figures 1-3), the mice injected with J591-SPMs did not suffer from any noticeable side effects or complications over the 20 days that the mice were followed after injection.

J591, a monoclonal antibody raised against PSMA, has been used in numerous clinical trials for prostate cancer. ${ }^{44-49}$ Our data show that J591 conjugated to paclitaxel-loaded micelles specifically target the micelles to human prostate cancer cells and prevent tumor growth in a PSMA-dependent manner. PSMA is highly expressed in almost all primary and metastatic prostate cancer tumors. ${ }^{50}$ Our data suggest that drug-loaded micelles targeted to PSMA could successfully treat prostate cancer tumors while possibly reducing the side effects commonly seen when using chemotherapeutics alone. Moreover, PSMA has been shown to be expressed in the neovasculature of almost all solid tumors, but not in healthy vasculature, ${ }^{50}$ supporting the idea that PSMA-targeting may be beneficial not only as a prostate cancer targeting motif but also as a general cancer target. In addition to the specific, targeted killing of PSMA-positive prostate cancer cells, ours is also the first report of encapsulating SIPPs with a chemotherapeutic drug in a mixture of functionalized and fluorescent phospholipids to produce multifunctional, iron platinum, stealth immunomicelles for specific MRI and treatment of cancer.

\section{Acknowledgments}

This research was supported in part by funding from the National Institutes of Health (5RO1CA123194 to LOS) and the NCI New Mexico Cancer Nanotechnology Training Center (NIH R25CA153825 supporting RMT). Portions of this work were performed at the Center for Integrated Nanotechnologies, a US Department of Energy, Office of Basic Energy Sciences, user facility. Sandia National Laboratories is a multiprogram laboratory operated by The Sandia Corporation, a Lockheed-Martin Company, for the US Department of Energy under Contract No DE-AC04-94AL85000. MRI was performed at the Brain Imaging Center, Albuquerque, NM. TEM images were generated at the UNM Electron Microscopy Facility. Some experiments used the facilities provided by the Keck-UNM Genomics Resource, a facility supported by grants from the WM Keck Foundation, the State of New Mexico, and the UNM Cancer Research and Treatment Center. We gratefully acknowledge the assistance of Medhi Ali of the Earth and Planetary Sciences Department at UNM, for the ICP-OES analyses, of Stephen Jett from the UNM Electron Microscopy Facility, and of Dale Huber from the Center for Integrated Nanotechnologies.

\section{Disclosure}

The authors report no conflicts of interest in this work.

\section{References}

1. Siegel R, Naishadham D, Jemal A. Cancer statistics, 2012. CA Cancer J Clin. 2012;62(1):10-29.

2. Moul JW, Dawson N. Quality of life associated with treatment of castration-resistant prostate cancer: a review of the literature. Cancer Invest. 2012;30(1):1-12.

3. Beltran H, Beer TM, Carducci MA, et al. New therapies for castration-resistant prostate cancer: efficacy and safety. Eur Urol. 2011;60(2):279-290.

4. Dayyani F, Gallick GE, Logothetis CJ, Corn PG. Novel therapies for metastatic castrate-resistant prostate cancer. J Natl Cancer Inst. 2011; 103(22):1665-1675.

5. Gomella LG, Gelpi F, Kelly WK. New treatment options for castrateresistant prostate cancer: a urology perspective. Can J Urol. 2011;18(4): 5767-5777.

6. Petrylak DP. Current clinical trials in castrate-resistant prostate cancer. Curr Urol Rep. 2011;12(3):173-179.

7. Abeylath SC, Ganta S, Iyer AK, Amiji M. Combinatorial-designed multifunctional polymeric nanosystems for tumor-targeted therapeutic delivery. Acc Chem Res. 2011;44(10):1009-1017. 
8. Ho D, Sun X, Sun S. Monodisperse magnetic nanoparticles for theranostic applications. Acc Chem Res. 2011;44(10):875-882.

9. Kievit FM, Zhang M. Surface engineering of iron oxide nanoparticles for targeted cancer therapy. Acc Chem Res. 2011;44(10):853-862

10. Koo H, Huh MS, Sun IC, et al. In vivo targeted delivery of nanoparticles for theranosis. Acc Chem Res. 2011;44(10):1018-1028.

11. Namiki Y, Fuchigami T, Tada N, et al. Nanomedicine for cancer: lipid-based nanostructures for drug delivery and monitoring. Acc Chem Res. 2011;44(10):1080-1093.

12. Shi J, Xiao Z, Kamaly N, Farokhzad OC. Self-assembled targeted nanoparticles: evolution of technologies and bench to bedside translation. Acc Chem Res. 2011;44(10):1123-1134.

13. Yoo D, Lee JH, Shin TH, Cheon J. Theranostic magnetic nanoparticles. Acc Chem Res. 2011;44(10):863-874.

14. Puri A, Blumenthal R. Polymeric lipid assemblies as novel theranostic tools. Acc Chem Res. 2011;44(10):1071-1079.

15. Sawant RR, Torchilin VP. Multifunctionality of lipid-core micelles for drug delivery and tumour targeting. Mol Membr Biol. 2010;27(7): 232-246.

16. Arias JL, Clares B, Morales ME, Gallardo V, Ruiz MA. Lipid-based drug delivery systems for cancer treatment. Curr Drug Targets. 2011;12(8):1151-1165.

17. Estella-Hermoso de Mendoza A, Campanero MA, Mollinedo F, Blanco-Prieto MJ. Lipid nanomedicines for anticancer drug therapy. J Biomed Nanotechnol. 2009;5(4):323-343.

18. Florence AT, Jani PU. Novel oral drug formulations. Their potential in modulating adverse effects. Drug Saf. 1994;10(3):233-266.

19. Peng XH, Qian X, Mao H, et al. Targeted magnetic iron oxide nanoparticles for tumor imaging and therapy. Int $J$ Nanomedicine. 2008;3(3):311-321.

20. Akhter S, Ahmad Z, Singh A, et al. Cancer targeted metallic nanoparticle: targeting overview, recent advancement and toxicity concern. Curr Pharm Des. 2011;17(18):1834-1850.

21. Hirsjarvi S, Passirani C, Benoit JP. Passive and active tumour targeting with nanocarriers. Curr Drug Discov Technol. 2011;8(3):188-196.

22. Zhang C, Liu T, Gao J, Su Y, Shi C. Recent development and application of magnetic nanoparticles for cell labeling and imaging. Mini Rev Med Chem. 2010;10(3):193-202.

23. Lin MM, Kim do K, El Haj AJ, Dobson J. Development of superparamagnetic iron oxide nanoparticles (SPIONS) for translation to clinical applications. IEEE Trans Nanobioscience. 2008;7(4): 298-305.

24. Shubayev VI, Pisanic TR 2nd, Jin S. Magnetic nanoparticles for theragnostics. Adv Drug Deliv Rev. 2009;61(6):467-477.

25. Mailander V, Landfester K. Interaction of nanoparticles with cells Biomacromolecules. 2009;10(9):2379-2400.

26. Gandhi SN, Brown MA, Wong JG, Aguirre DA, Sirlin CB. MR contrast agents for liver imaging: what, when, how. Radiographics. 2006;26(6):1621-1636.

27. Tsukada H. Application of pre-clinical PET imaging for drug development. Nihon Shinkei Seishin Yakurigaku Zasshi. 2011;31(5-6): 231-237. Japanese.

28. Taylor RM, Huber DL, Monson TC, Esch V, Sillerud LO. Structural and magnetic characterization of superparamagnetic iron platinum nanoparticle contrast agents for magnetic resonance imaging. $J$ Vac Sci Technol B. 2012;30(2).

29. Taylor RM, Huber DL, Monson TC, Ali AM, Bisoffi M, Sillerud LO. Multifunctional iron platinum stealth immunomicelles: targeted detection of human prostate cancer cells using both fluorescence and magnetic resonance imaging. J Nanopart Res. 2011;13(10):4717-4729.

30. Rasband WS. ImageJ. US National Institutes of Health, Bethesda, Maryland, USA, 1997-2009. Available from: http//rsb.info.nih.gov/ ij/. Accessed July 4, 2012.
31. Gossuin Y, Gillis P, Hocq A, Vuong QL, Roch A. Magnetic resonance relaxation properties of superparamagnetic particles. Wiley Interdiscip Rev Nanomed Nanobiotechnol. 2009;1(3):299-310.

32. Huang J, Zhong X, Wang L, Yang L, Mao H. Improving the magnetic resonance imaging contrast and detection methods with engineered magnetic nanoparticles. Theranostics. 2012;2(1):86-102.

33. Lee JH, Huh YM, Jun YW, et al. Artificially engineered magnetic nanoparticles for ultra-sensitive molecular imaging. Nat Med. 2007; 13(1):95-99.

34. Carroll MR, Huffstetler PP, Miles WC, et al. The effect of polymer coatings on proton transverse relaxivities of aqueous suspensions of magnetic nanoparticles. Nanotechnology. 2011;22(32):325702.

35. Diezi TA, Bae Y, Kwon GS. Enhanced stability of PEG-block-poly(Nhexyl stearate 1-aspartamide) micelles in the presence of serum proteins. Mol Pharm. 2010;7(4):1355-1360.

36. Kastantin M, Missirlis D, Black M, Ananthanarayanan B, Peters D, Tirrell M. Thermodynamic and kinetic stability of DSPE-PEG(2000) micelles in the presence of bovine serum albumin. $J$ Phys Chem $B$. 2010;114(39):12632-12640.

37. Lu J, Owen SC, Shoichet MS. Stability of self-assembled polymeric micelles in serum. Macromolecules. 2011;44(15):6002-6008.

38. Taylor RM, Severns V, Brown DC, Bisoffi M, Sillerud LO. Prostate cancer targeting motifs: Expression of alpha(nu) beta(3), neurotensin receptor 1, prostate specific membrane antigen, and prostate stem cell antigen in human prostate cancer cell lines and xenografts. Prostate. 2012;72(5):523-532.

39. Couraud S, Planus C, Rioufol C, Mornex F. Platinum salts hypersensitivity. Rev Pneumol Clin. 2008;64(1):20-26. French.

40. Cristaudo A, Sera F, Severino V, De Rocco M, Di Lella E, Picardo M. Occupational hypersensitivity to metal salts, including platinum, in the secondary industry. Allergy. 2005;60(2):159-164.

41. Touraine F, Sainte Laudy J, Boumediene A, et al. Investigation of allergic reactions to platinum salts. Rev Mal Respir. 2006;23(5 Pt 1): 458-462. French.

42. Zhao J, Kim JE, Reed E, Li QQ. Molecular mechanism of antitumor activity of taxanes in lung cancer. Int J Oncol. 2005;27(1): 247-256.

43. Nie S. Understanding and overcoming major barriers in cancer nanomedicine. Nanomedicine (Lond). 2010;5(4):523-528.

44. Akhtar NH, Pail O, Saran A, Tyrell L, Tagawa ST. Prostate-specific membrane antigen-based therapeutics. Adv Urol. 2012;2012:973820.

45. Bander NH, Trabulsi EJ, Kostakoglu L, et al. Targeting metastatic prostate cancer with radiolabeled monoclonal antibody J591 to the extracellular domain of prostate specific membrane antigen. J Urol. 2003; 170(5):1717-1721.

46. Bayes M, Rabasseda X, Prous JR. Gateways to clinical trials. Methods Find Exp Clin Pharmacol. 2007;29(6):427-437.

47. Nanus DM, Milowsky MI, Kostakoglu L, et al. Clinical use of monoclonal antibody HuJ591 therapy: targeting prostate specific membrane antigen. J Urol. 2003;170(6 Pt 2):S84-S88.

48. Rice SL, Roney CA, Daumar P, Lewis JS. The next generation of positron emission tomography radiopharmaceuticals in oncology. Semin Nucl Med. 2011;41(4):265-282.

49. Tagawa ST, Beltran H, Vallabhajosula S, et al. Anti-prostate-specific membrane antigen-based radioimmunotherapy for prostate cancer. Cancer. 2010;116(4 Suppl):1075-1083.

50. Chang SS, O'Keefe DS, Bacich DJ, Reuter VE, Heston WD, Gaudin PB. Prostate-specific membrane antigen is produced in tumor-associated neovasculature. Clin Cancer Res. 1999;5(10):2674-2681. 


\section{Supplementary figures}

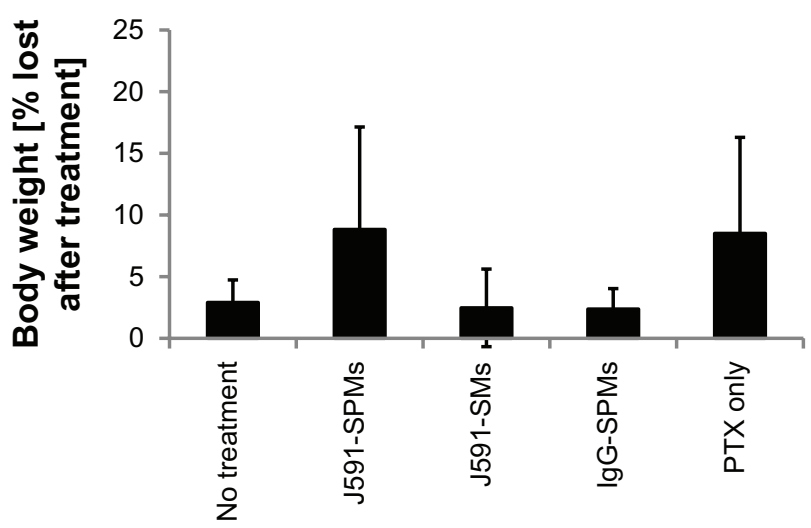

Figure SI Body weights of mice bearing C4-2 xenografts that were injected with treatments or controls.

Notes: Mice bearing C4-2 human prostate cancer cell xenografts were injected with the treatments or controls and weighed on the day of injection and on the day of euthanasia. None of the mice showed significant differences in loss of body weight over the 20 days.

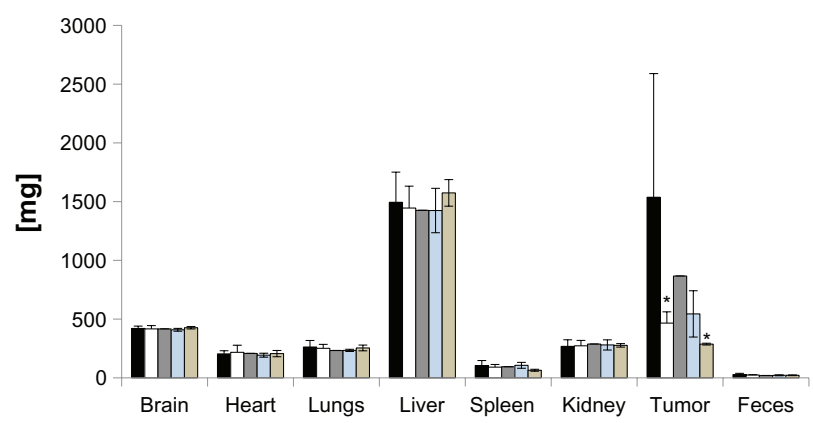

Figure S2 Tissue weights of mice bearing C4-2 xenografts that were injected with treatments or controls.

Notes: Mice bearing C4-2 xenografts were injected with J59I-SPMs (white bars), J59I-SMs (gray bars), IgG-SPMs (blue bars), PTX alone (beige bars), or nothing (black bars) and 20 days later their tissues and tumors were collected and weighed. None of the mice showed significant differences in tissue weights post-mortem, although the mice injected with PTX alone, J59I-SPMs, and IgG-SPMs showed decreased tumor mass compared to mice injected with SIPP-micelles without drug and mice that were not injected. *corresponds to significance of $P<0.05$.

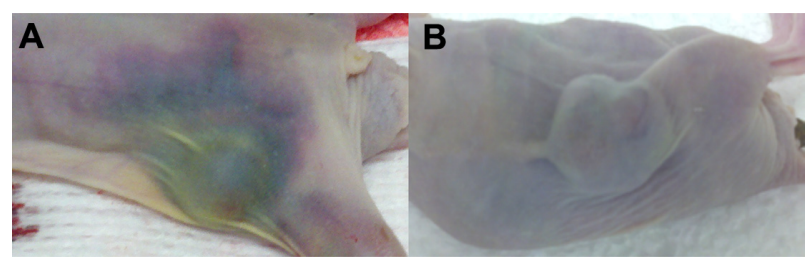

Figure S3 Hematoma around the tumors of mice injected with PTX alone. Representative images are shown for mice injected with PTX alone (A) and J59I-SPMs (B) taken post-mortem. The mice injected with PTX alone clearly had extensive hematoma around the tumors and all along the right flanks, whereas the mice injected with J59I-SPMs did not have this side effect, suggesting that in addition to targeting the drug, encapsulation of the drug also reduced side effects.
International Journal of Nanomedicine

\section{Publish your work in this journal}

The International Journal of Nanomedicine is an international, peerreviewed journal focusing on the application of nanotechnology in diagnostics, therapeutics, and drug delivery systems throughout the biomedical field. This journal is indexed on PubMed Central, MedLine, CAS, SciSearch ${ }^{\circledR}$, Current Contents ${ }^{\circledR} /$ Clinical Medicine,

\section{Dovepress}

Journal Citation Reports/Science Edition, EMBase, Scopus and the Elsevier Bibliographic databases. The manuscript management system is completely online and includes a very quick and fair peer-review system, which is all easy to use. Visit http://www.dovepress.com/ testimonials.php to read real quotes from published authors. 